doi: 10.7250/iscconstrs.2014.06

\title{
OPTIMAL DESIGN OF RATIONAL FIBER ORIENTATION FOR VARIABLE STIFFNESS PLYWOOD-PLASTIC PLATE - NUMERICAL AND EXPERIMENTAL INVESTIGATIONS
}

\author{
Girts Frolovs $^{1}$, Janis Sliseris ${ }^{2}$, Karlis Rocens ${ }^{3}$, Vadims Goremikins ${ }^{4}$ \\ ${ }^{1,2,3,4}$ Department of Structural Engineering, Faculty of Building and Civil Engineering, Riga Technical University, \\ Kalku st. 1, LV-1001 Riga, Latvia

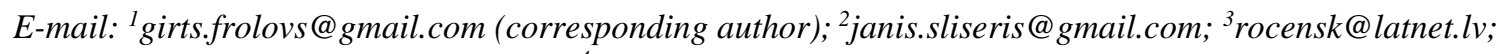 \\ ${ }^{4}$ goremikins@gmail.com;
}

\begin{abstract}
The new optimization method of outer layer fiber directions and concentrations of plywood plate with glass fiber-vinyl ester resin outer layers are proposed. The method minimizes structural compliance. It consists of two phases. The fiber directions are optimized in the first phase and concentrations in the second phase. The increase of stiffness is about $30 \%$ of plate with optimized fiber direction and concentration comparing to similar non-optimized plate.
\end{abstract}

Key words: Plywood, Glass fiber, fiber orientation, fiber concentration, minimal compliance, optimization method

\section{Introduction}

Laminated plates and shells with variable stiffness have been intensively introduced investigated and widely used during past two decades.

An optimal variable stiffness plate could be obtained by optimization of fiber orientation angle (Keller, 2010; Pelletier, Vel, 2006; Gurdal, Olmedo, 1993) or thickness optimization (Almeida, Awruch, 2009; Muc, MucWierzgon, 2012). A lamina with the variable stiffness and curved fibers provide a great flexibility to achieve needed natural frequencies, mode shapes (Akhavan, Ribeiro, 2011), vibration amplitudes (Akhavan, Ribeiro, 2012) and buckling load (Setoodeh et. al., 2009).

Genetic Algorithm could be used to optimize these plates(Sliseris, Rocens, 2011; Sliseris, Rocens, 2012) or Ant Colony algorithm for more complicated objective function (Sebaey et. al., 2011; Wang et. al, 2010; Hudson et. al., 2010) Problem of optimal fiber orientation angle of multilayer lamina is successfully solved by the using of topology optimization approach (Diaz, Bendsoe, 1992; Bendsoe, 1989), discrete material optimization method (Lund, 2009; Niu et.al., 2010; Stegmann, Lund, 2005), Ant colony algorithm (Kaveh et.al., 2008) or Genetic algorithm (Hansel et.al., 2002). uncertainty and nonlinear effects and uncertainty could be taken into account (Jung, Cho, 2004; Asadpoure et. al., 2011).

This paper is proposing an improved and tailored multilayeroptimization method for fiber directions and concentrations in outer layers and showed some typical results as well as some experimental investigations of these plates.

\section{Optimization method}

Tailored optimization method for variable stiffness plates is provided. Two stage optimization of plates outer layers is provided which optimizes fiber directions in the first step and fiber concentrations in the second. This method is based on structural compliance minimization:

$$
\begin{aligned}
& \min _{\phi, k} U^{T}(\phi, k) K(\phi, k) U(\phi, k), \\
& \text { where } \phi \text { - fiber orientation angles; } \\
& U(\phi, k) \text { - displacement vector; } \\
& K(\phi, k)-\text { global stiffness matrix. } \\
& \phi=\left\{\phi_{1}, \phi_{2}, \ldots, \phi_{N e}\right\}, \\
& k=\left\{k_{1}, k_{2}, \ldots, k_{N e}\right\} .
\end{aligned}
$$

Since the outer layers ply the most significant role in stiffness of flexural plate this method optimizes only fiber directions and concentrations in the outer layer (GFRP layers) of plate.

The material flexural stiffness matrix $D_{i}$ of i-th finite element is modified by using coordinate transformation matrix $\mathrm{N}$ and fiber concentration coefficients $\mathrm{k}$ :

$$
D_{i}=k_{i} N^{T}\left(\phi_{i}\right) D_{i}^{0} N\left(\phi_{i}\right) .
$$

The proposed method is based on algorithm that is shown in fig. 1. The algorithm consists of three loops. The first loop runs until the convergence criteria are satisfied. The second loop goes through all finite elements from 1 to $\mathrm{Ne}$ (number of finite elements). The third loop goes through all discrete values of fiber orientation angles from $l$ to $N$.

The fiber orientation angles are changed by special procedure $R(x)=x_{j}$. This procedure changes orientation angle to $x_{j}$ in region with center in $i$-th finite element and radius $R_{\text {inf }}$.

The finite element analysis is done inside all loops. The value of compliance function $C(i, j)$ (index $i$ indicate $i$-th discrete angle and index $j$ indicate $j$-th finite element) is calculated by using the results of finite element analysis.

There is a special procedure that updates values of fiber orientation angles $x$ inside the first loop. The updated value of $x$ is obtained in each finite element according to minimal compliance. 
The fiber concentrations are updated by using following algorithm:

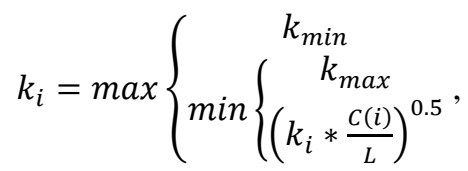

where $k_{\text {min }}, k_{\max }-$ minimal/maximal value of possible concentration;

$L$-parameter that is used to limit the sum of concentrations in all finite elements.

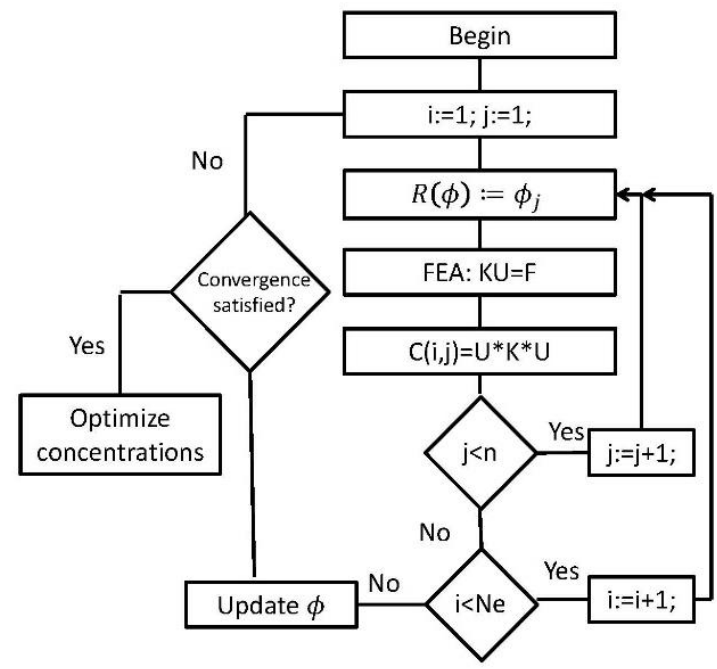

Fig. 1. Fiber direction $\phi$ optimization algorithm.

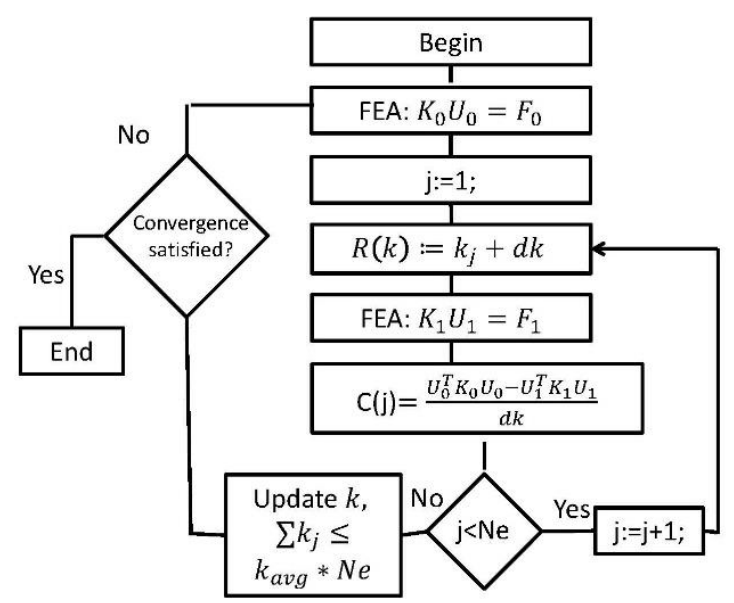

Fig. 2. Fiber concentration $k$ optimization algorithm.

\section{Results and discussion}

The optimal fiber orientation angles and concentration ratio for outer layers (top and bottom) were obtained for 19 layer symmetrical birch plywood sheet. The plywood sheet has the following lay-up $\left[\phi_{i}, 0,90, \ldots, 90,0, \phi_{i}\right]$. with the total thickness of plywood plate $26 \mathrm{~mm}$. For the outer layer of a plate glass fibers with vinyl ester resin matrix were taken.

The standard birch plywood were used with following elastic properties (Sliseris, Rocens, 2012): of a single sheet $E_{1}=16400 \mathrm{MPa}, E_{2}=500 \mathrm{MPa}, G_{12}=$
$890 \mathrm{MPa}, v_{12}=0.3$. The glass fiber of grade $\mathrm{E}$ was analyzed using the following elastic properties: $E_{1}=$ $E_{2}=85000 \mathrm{MPa}, G_{12}=35420 \mathrm{MPa}, v_{12}=v_{21}=0.2$ (Bank 2006). The vinyl ester resin glue was assumed to have the following elastic properties: $E_{1}=E_{2}=$ $3400 \mathrm{MPa}, v_{12}=v_{21}=0.3, G_{12}=1308 \mathrm{MPa}$ (Clarke, 2005)

Four discrete values of fiber orientation angle were used: 0/45/90/135. (The angle between outer layers of a plywood plate and fiber direction in outer layer of a whole composite plate) load

All plates are loaded by $1 \mathrm{kN} / \mathrm{m}^{2}$ uniformly distributed

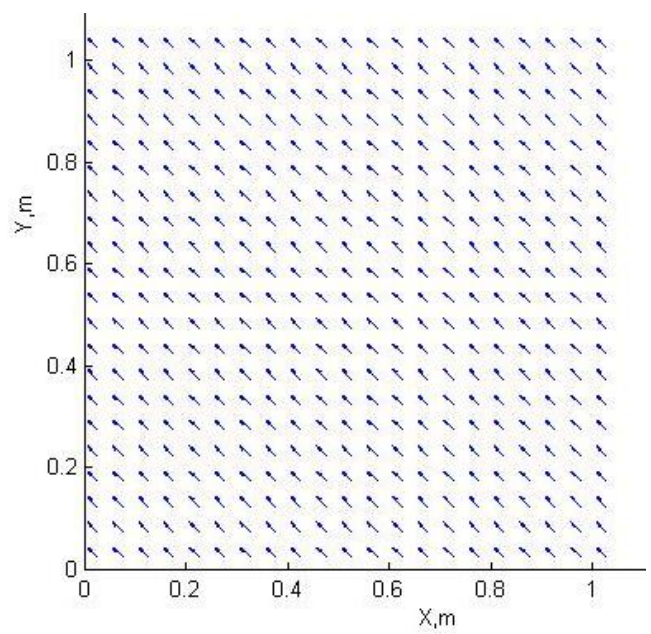

Fig. 3. Fiber direction plot of a single span rectangular plate with dimensions $2.1 \mathrm{~m} \times 2.1 \mathrm{~m}$ (due to symmetry shown one quarter of plate).

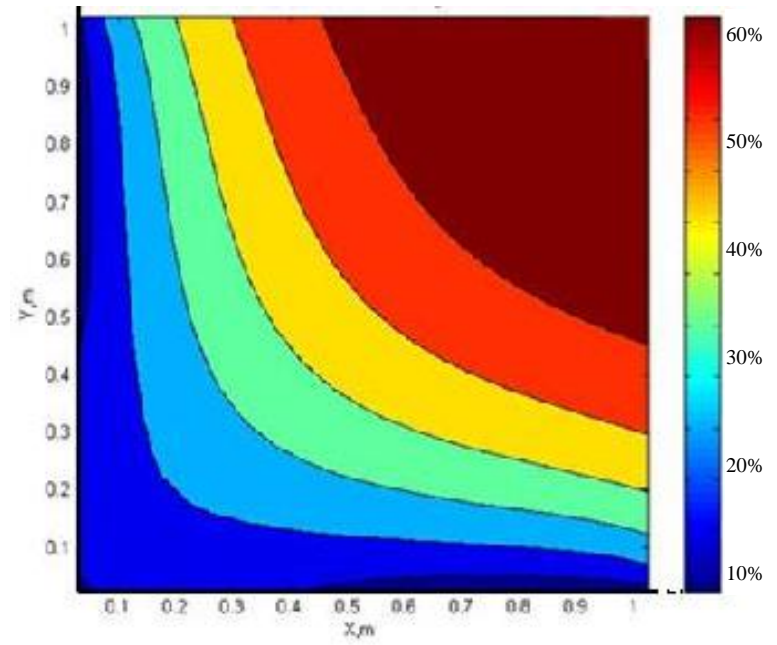

Fig. 4. Fiber relative concentration plot of a single span quadratic plate with dimensions $2.1 \mathrm{~m}$ x $2.1 \mathrm{~m}$ (due to symmetry shown one quarter of plate). 


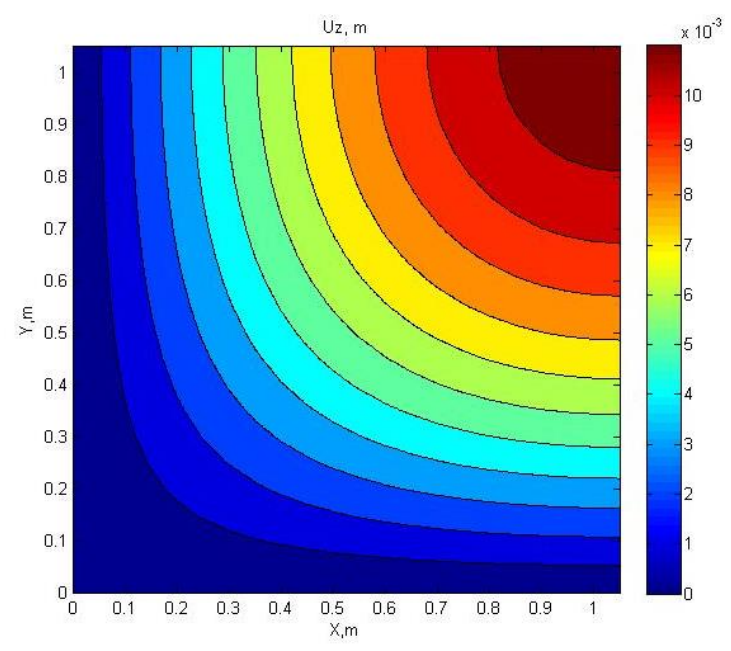

Fig. 5. Deflection plot of a single span quadratic non-optimized plate with dimensions $2.1 \mathrm{~m} \times 2.1 \mathrm{~m}$ (due to symmetry shown one quarter of plate).

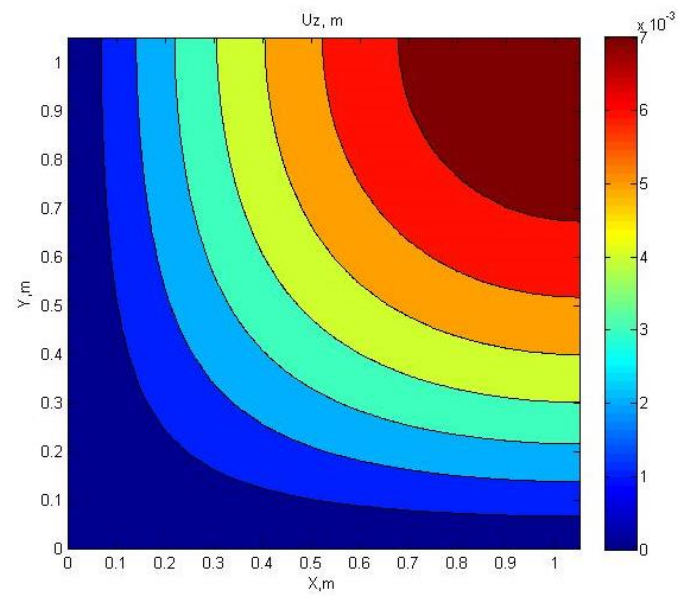

Fig. 6. Deflection plot of a single span quadratic optimized plate with dimensions $2.1 \mathrm{~m} \times 2.1 \mathrm{~m}$ (due to symmetry shown one quarter of plate).

The optimal fiber concentration plot is shown in Fig. 4. It can be seen that maximal amount of fiber should be put in the central part of plate.

The maximal deflection of non-optimized plate is $11.7 \mathrm{~mm}$; the plate's with optimized just fiber directions in outer layers- $10.1 \mathrm{~mm}$; the plate with optimized fiber directions and concentrations in outer layers- $8.0 \mathrm{~m}$.

The optimization was done also for three span plates (fig. 7.-10.). For these plates maximal fiber concentrations are necessary on support lines in opposite to one span plate.

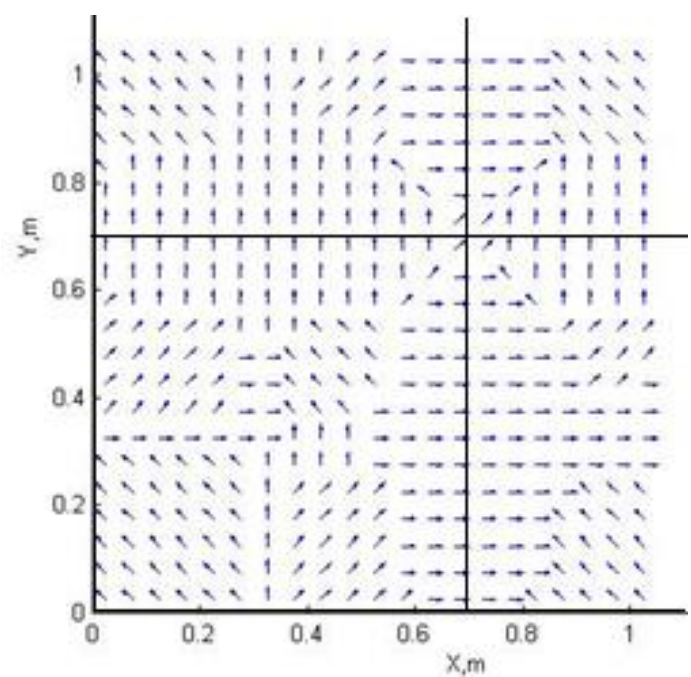

Fig. 7. Fiber direction plot of a three span rectangular plate with spans $0.7 \mathrm{~m} \times 0.7 \mathrm{~m} \times 0.7 \mathrm{~m}$ in both directions (due to symmetry shown one quarter of plate).

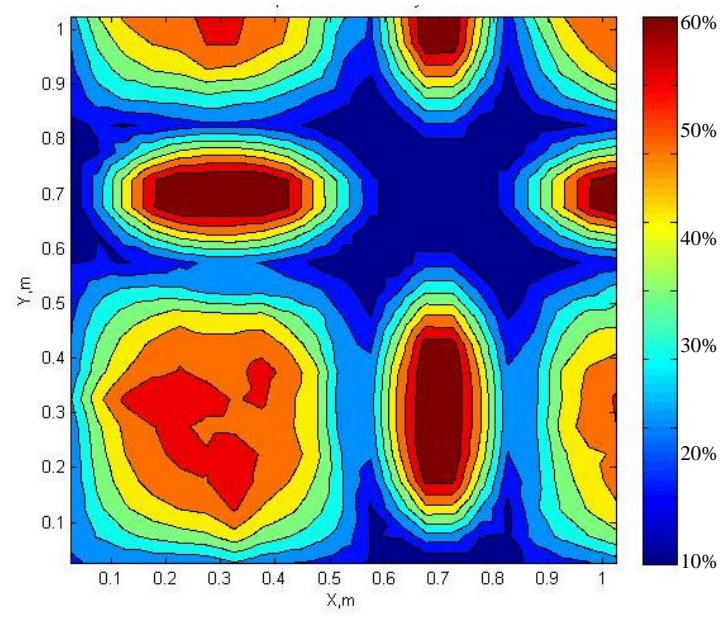

Fig. 8. Fiber relative concentration plot of a three span rectangular plate with spans $0.7 \mathrm{~m} \times 0.7 \mathrm{~m} \times 0.7 \mathrm{~m}$ in both directions (due to symmetry shown one quarter of plate).

It is obvious (fig. 3) that each quarter of a plate has constant fiber orientation angle. However, by optimization of the concentrations (fig. 4) more discrete areas should be chosen.

The three span plates (equal and different spans) could be divided in rectangular discrete domains (see fig. 7;fig. 8. and fig. 9; fig. 10) like it was in the case with one span plate but in this case with more discrete areas. 


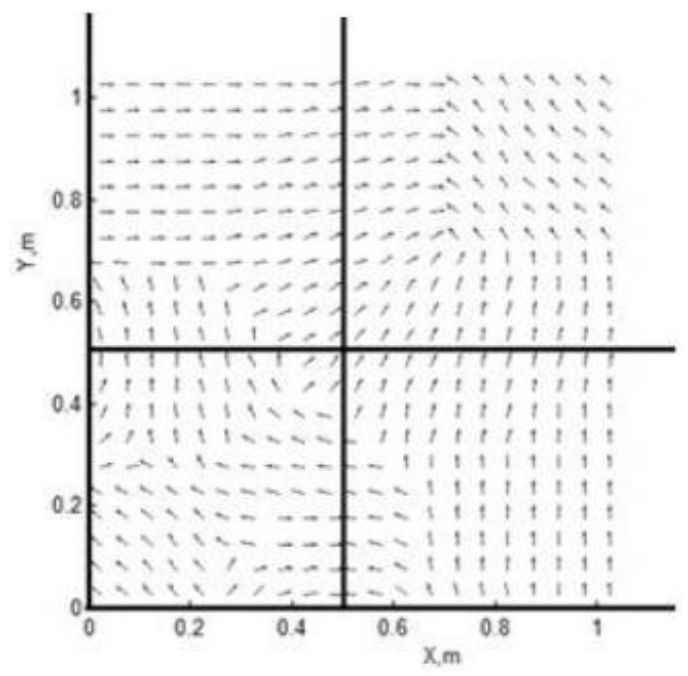

Fig. 9. Fiber direction plot of a three span rectangular plate with spans $0.5 \mathrm{~m} \times 1.1 \mathrm{~m} \times 0.5 \mathrm{~m}$ in both directions (due to symmetry shown one quarter of plate).

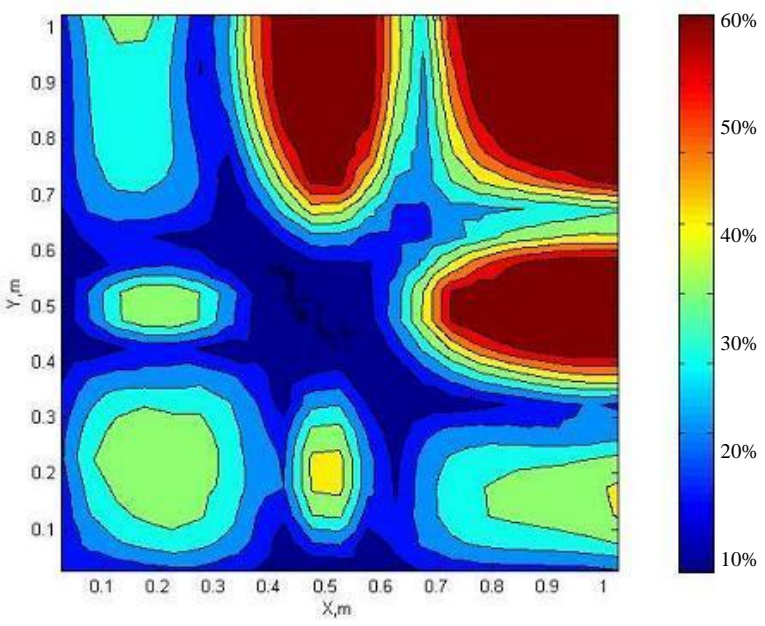

Fig. 10. Fiber relative concentration plot of a three span rectangular plate with spans $0.5 \mathrm{~m} \times 1.1 \mathrm{~m} \times 0.5 \mathrm{~m}$ in both directions (due to symmetry shown one quarter of plate).

\section{The behavior of a plate with discrete variable stiffness}

Composite with discrete variable stiffness is chosen to provide manufacturing possibilities of such plates. For each discrete area of a plate fiber orientation and concentrations are optimized. Only four discrete fiber orientation values for fiber angles (0/45/90/135 degrees) and four values for relative concentrations $\mathrm{k}$ (15\%/25\%/40\%/60\%) were chosen;

In the first case there are constant directions of outer layer, in second case there are optimized fiber directions of glass fibers (0/45/90/135 degrees) in outer layers, and in third there are optimized outer fiber directions and concentrations of outer layers with previously provided four discrete values for fiber angels and four discrete values for fiber directions.

Reduced modulus of elasticity (for relative concentration $30 \%$ ) for glass fiber-vinyl ester layer is calculated (Bank 2006) $\mathrm{E}_{1}=28000 \mathrm{MPa} ; \mathrm{E}_{2}=\mathrm{E}_{3}=6200$
$\mathrm{MPa} ; \mathrm{G}_{12}=\mathrm{G}_{13}=2700 \mathrm{MPa} ; \mathrm{G}_{23}=1500 \mathrm{MPa} ; v_{12}=v_{23}=0,27$; $v_{13}=0.044$

The thickness of GFRP layer is $1.5 \mathrm{~mm}$, but the thickness of each plywood layer is $1.42 \mathrm{~mm}$. The chosen discrete domains for three equal span plate of discrete areas with intensities are shown in fig. 11.

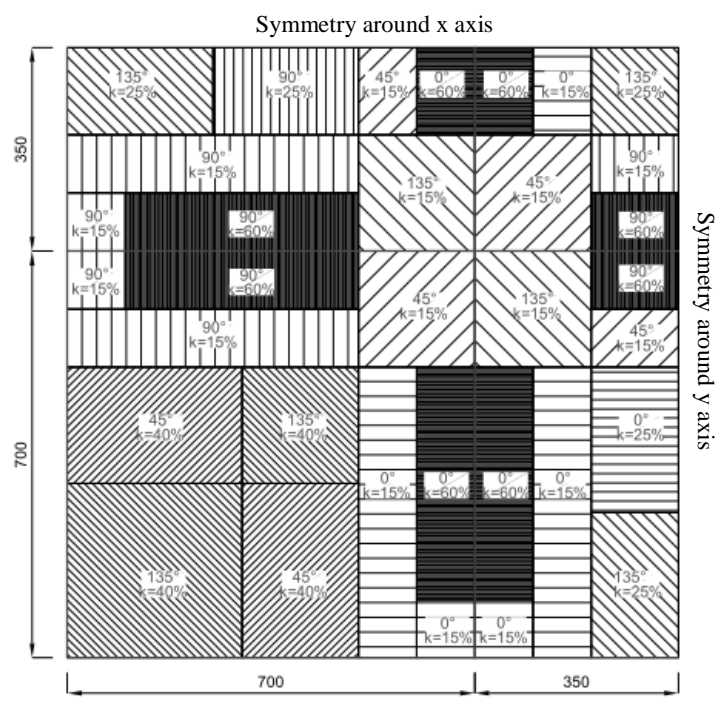

Fig. 11. The plot of simply rectangular discrete domains including fiber orientations and concentrations of a three equal span rectangular plate with spans $0.7 \mathrm{~m} \mathrm{x} 0.7 \mathrm{~m} \times 0.7 \mathrm{~m}$ in both directions (due to symmetry shown one quarter of plate).

The plate with three equal spans are loaded by 10 $\mathrm{kN} / \mathrm{m}^{2}$ uniformly distributed load the same as for three different span plate example. Due to symmetry, one quarter of plate was analysed.

Fig. 12. Deflection plot of a three equal span quadratic plate

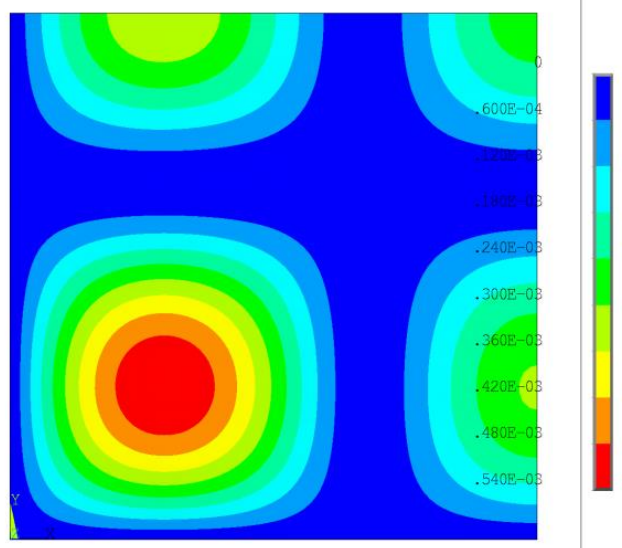

$(0.7 \mathrm{~m} \times 0.7 \mathrm{~m} \times 0.7 \mathrm{~m})$ in both directions for non-optimized plate with extra ply sheet (due to symmetry shown one quarter of plate). 

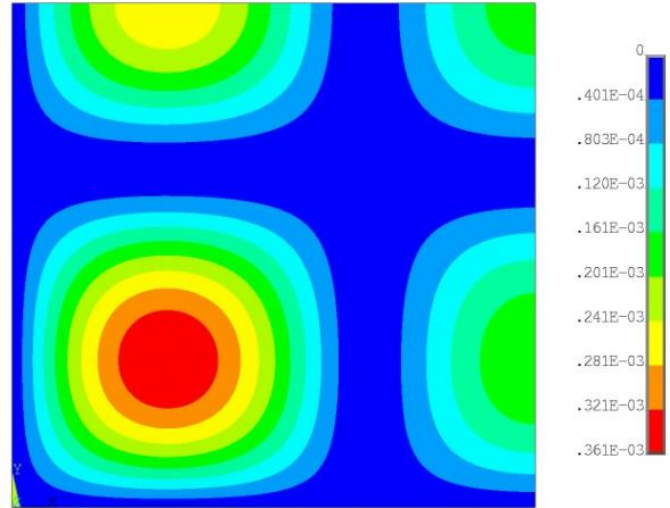

Fig. 13. Deflection plot of a three equal span quadratic rectangular plate with spans $(0.7 \mathrm{~m} \times 0.7 \mathrm{~m} \times 0.7 \mathrm{~m})$ in both directions for non-optimized plate (due to symmetry shown one quarter of plate).
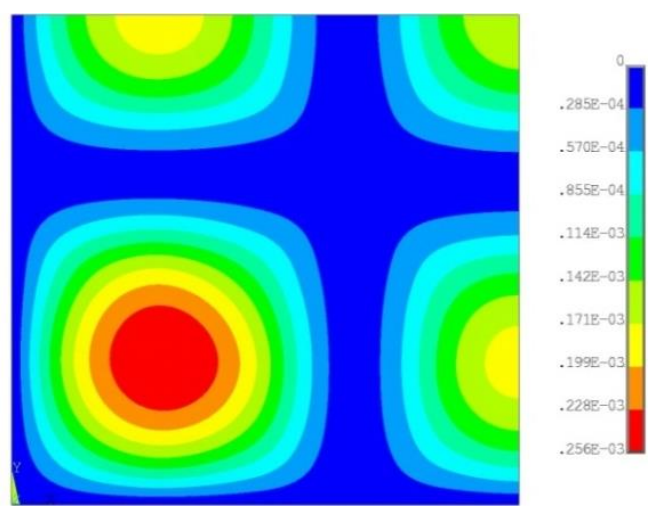

Fig. 14. Deflection plot of a three equal span quadratic rectangular plate with spans $(0.7 \mathrm{~m} \times 0.7 \mathrm{~m} \times 0.7 \mathrm{~m})$ in both directions with optimized fiber directions and constant (30\%) concentrations (due to symmetry shown one quarter of plate).
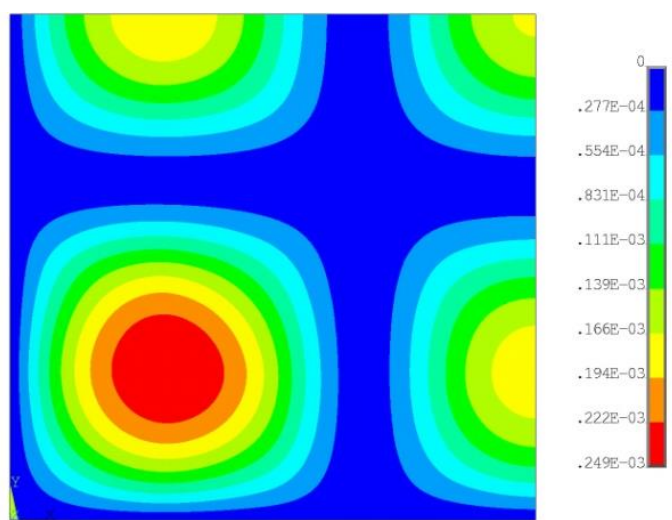

Fig. 15. Deflection plot a three equal span quadratic rectangular plate with spans $(0.7 \mathrm{~m} \times 0.7 \mathrm{~m} \times 0.7 \mathrm{~m})$ in both directions with optimized fiber directions and concentrations with the average concentration $30 \%$. (due to symmetry shown one quarter of plate)

The maximal deflection of a ply-wood with thickness of $30 \mathrm{~mm}$ is $0.504 \mathrm{~mm}$ (see fig. 12), for non-optimized $(27 \mathrm{~mm})$ plate with extra fiberglass-resin layers is $0.398 \mathrm{~mm}$ (see fig. 13). In the case with optimized fiber directions and constant concentrations the maximal deflection is $0.334 \mathrm{~m}$ (see fig. 14) and for the plate with optimized fiber directions and concentrations in outer layers the maximal deflections is $0.287 \mathrm{~m}$ (see fig. 15). The comparison between all cases is shown in table 1 .

It is found that the decrease of displacements is $16 \%$ when optimized only fiber directions and $28 \%$ when optimized fiber directions and concentrations) by using fiberglass vinyl ester resinlayers, but when optimized directions of extra outer ply sheet the decrease of displacements are about $16 \%$. It shows that by optimization of fiber directions it is the same improvement achieved by using either extra ply sheets or fiberglass fiberglass vinyl ester resinlayers in outer layer.

The maximum displacements were in the middle of first and last span of the plate for the three span plate.

It is achieved that the ultimate strength is achieved in ply wood sheets, therefore the values of stresses in directions of ply veneers is needed to analyze.

Table 1. Comparison of maximal deflection (m) for different variants

\begin{tabular}{|c|c|c|c|c|}
\hline Comparison of deflections & $\begin{array}{c}\text { Deflection } \\
\mathrm{w}[\mathrm{mm}]\end{array}$ & $\begin{array}{l}\text { Improvement } \\
\text { to } \\
27 \mathrm{~mm} \mathrm{Ply} \\
\text { wood \% }\end{array}$ & $\begin{array}{l}\text { Improvement } \\
\text { to } \\
30 \mathrm{~mm} \text { Ply } \\
\text { wood \% }\end{array}$ & $\begin{array}{l}\text { Improvement to } \\
27 \text { mm Ply wood } \\
\text { with extra } \\
\text { fiberglass layer\% }\end{array}$ \\
\hline Ply wood 27mm: & 0.658 & $0 \%$ & & \\
\hline Ply wood 30mm: & 0.504 & $23 \%$ & $0 \%$ & \\
\hline $\begin{array}{l}\text { Ply wood } 27 \mathrm{~mm}+\text { outer layers } 1,5 \mathrm{~mm} \\
\text { extra ply sheets with optimized } \\
\text { directions: }\end{array}$ & 0.424 & $36 \%$ & $16 \%$ & \\
\hline $\begin{array}{l}\text { Ply wood } 27 \mathrm{~mm}+\text { outer layers } 1,5 \mathrm{~mm} \\
\text { non optimized extra fiberglass-epoxy } \\
\text { layers : }\end{array}$ & 0.398 & $40 \%$ & $21 \%$ & $0 \%$ \\
\hline
\end{tabular}




\begin{tabular}{|l|c|c|c|c|}
\hline $\begin{array}{l}\text { Ply wood 27mm + outer layers 1,5 mm } \\
\text { extra fiberglass-epoxy layers with } \\
\text { optimized directions : }\end{array}$ & 0.334 & $49 \%$ & $34 \%$ & $16 \%$ \\
$\begin{array}{l}\text { Ply wood 27mm + outer layers 1,5 mm } \\
\text { extra fiberglass-epoxy layers with } \\
\text { optimized directions and } \\
\text { concentrations: }\end{array}$ & 0.287 & $56 \%$ & $43 \%$ & $28 \%$ \\
\hline
\end{tabular}

Table 2 Comparison of maximal stress in direction of wood fiber for different variants

\begin{tabular}{|c|c|c|c|c|}
\hline Comparison of deflections & $\begin{array}{l}\text { Stresses } \sigma \\
\quad[\mathrm{MPa}]\end{array}$ & $\begin{array}{c}\text { Improvement } \\
\text { to } \\
27 \mathrm{~mm} \mathrm{Ply} \\
\text { wood \% }\end{array}$ & $\begin{array}{c}\text { Improvement } \\
\text { to } \\
30 \mathrm{~mm} \mathrm{Ply} \\
\text { wood \% }\end{array}$ & $\begin{array}{c}\text { Improvement to } \\
27 \text { mm Ply wood } \\
\text { with extra } \\
\text { fiberglass-epoxy } \\
\text { layer\% }\end{array}$ \\
\hline Ply wood $27 \mathrm{~mm}$ : & 5.767 & $0 \%$ & & \\
\hline Ply wood 30mm: & 3.980 & $31 \%$ & $0 \%$ & \\
\hline $\begin{array}{l}\text { Ply wood } 27 \mathrm{~mm}+\text { outer layers } 1,5 \mathrm{~mm} \\
\text { extra ply sheets with optimized } \\
\text { directions: }\end{array}$ & 3.710 & $36 \%$ & $7 \%$ & \\
\hline $\begin{array}{l}\text { Ply wood } 27 \mathrm{~mm}+\text { outer layers } 1,5 \mathrm{~mm} \\
\text { non optimized extra fiberglass layers : }\end{array}$ & 3.097 & $46 \%$ & $22 \%$ & $0 \%$ \\
\hline $\begin{array}{l}\text { Ply wood } 27 \mathrm{~mm}+\text { outer layers } 1,5 \mathrm{~mm} \\
\text { extra fiberglass layers with optimized } \\
\text { directions : }\end{array}$ & 2.879 & $50 \%$ & $28 \%$ & $7 \%$ \\
\hline $\begin{array}{l}\text { Ply wood } 27 \mathrm{~mm}+\text { outer layers } 1,5 \mathrm{~mm} \\
\text { extra fiberglass layers with optimized } \\
\text { directions and concentrations: }\end{array}$ & 2.163 & $62 \%$ & $46 \%$ & $30 \%$ \\
\hline
\end{tabular}

The values of stresses in directions of veneers reduce for $7 \%$ with optimization of fiber directions in both cases (ply sheets and fiberglass layer) and 30\% with optimization of fiber directions and concentrations in case of fiberglass layers). All values of stresses for three equal span plate are shown in table 2.
The similar improvement is achieved with three different span plate (fig. 16) - $16 \%$ increase of stiffness when optimized outer layer directions (in both cases) and $35 \%$ when optimized outer layer directions and concentrations in case of using fiberglass laminates.

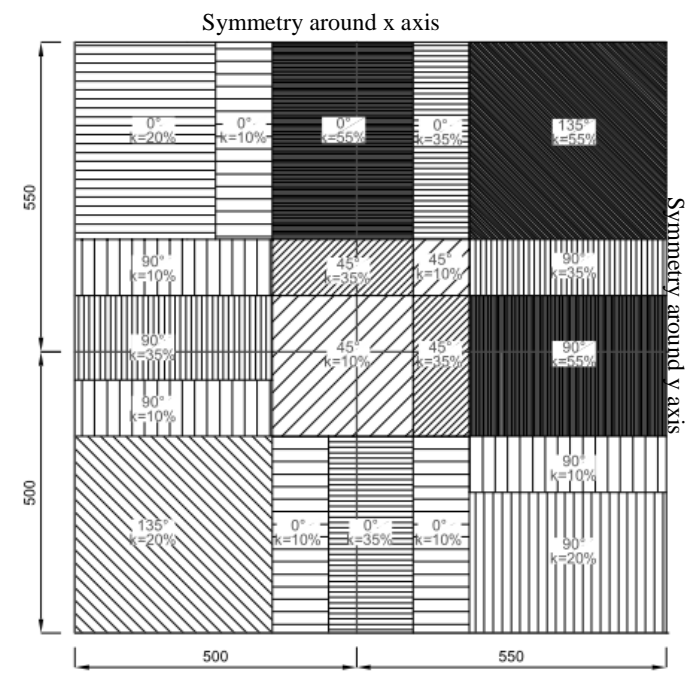

Fig. 16. The plot of simply rectangular discrete domains including fiber orientations and concentrations of a three different span rectangular plate with spans $0.5 \mathrm{~m} \times 1.1 \mathrm{~m} \times 0.5 \mathrm{~m}$ in both directions (due to symmetry shown one quarter of plate). 
For one span plate (fig. 17) the most increase of stiffness were achieved by optimization of fiber directions - $23 \%$ but when optimized directions and concentrations the increase of stiffness was $27 \%$. The chosen discrete areas of outer layer angles were very accurate to theoretical optimal result scheme.

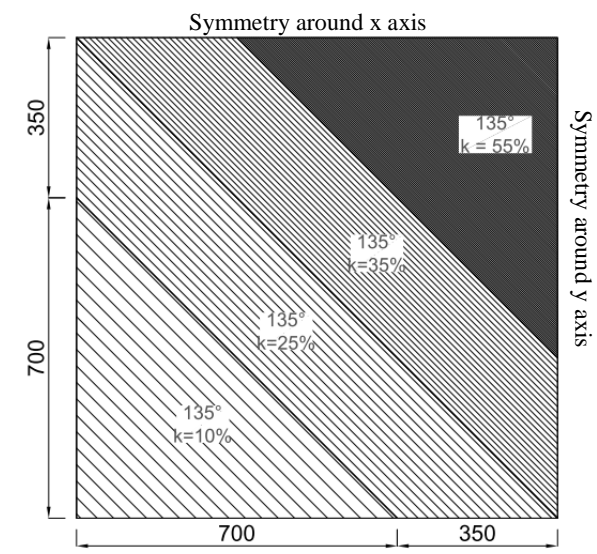

Fig. 17. The plot of simply rectangular discrete domains including fiber orientations and concentrations of a one span rectangular plate with spans $2.1 \mathrm{~m}$ in both directions (due to symmetry shown one quarter of plate).

\section{Experimental investigations}

Some experimental investigations were done for contour supported square plates with non-optimized and optimized outer fiberglass layer. The thickness of plywood was $6.5 \mathrm{~mm}$, and thickness of fiberglass layer was $1.0 \mathrm{~mm}$. Two different types of specimens were investigated $-6.5 \mathrm{~mm}$ plywood with 2 layers of fiberglass layers in both sides of a plate with total thickness $10.5 \mathrm{~mm}$ and $6.5 \mathrm{~mm}$ plywood with 3 layers of fiberglass layers in both sides of a plate with total thickness $10.5 \mathrm{~mm}$. The compared vales between theoretical and experimental values are mostly in $10 \%$ limitation with more congruence at higher loadings. The values are shown in Table 3 .

Table 3. Experimental investigations of optimized and non-optimized contour supported square plates.

\begin{tabular}{|c|c|c|c|c|c|c|c|c|c|c|c|c|c|c|c|}
\hline \multirow[b]{2}{*}{ 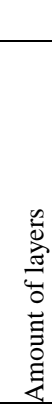 } & & & & & & \multicolumn{5}{|c|}{ Stiffness } & \multicolumn{5}{|c|}{ Strength } \\
\hline & $\begin{array}{ll}0 \\
\\
\end{array}$ & 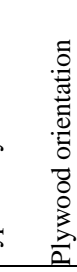 & 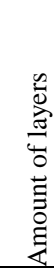 & 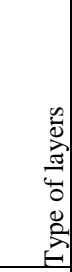 & 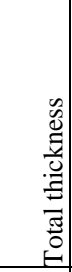 & 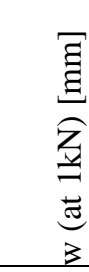 & & 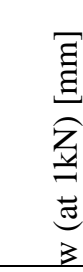 & 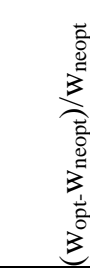 & 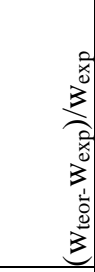 & $\underset{\underbrace{}}{\underset{\text { Z }}{Z}}$ & 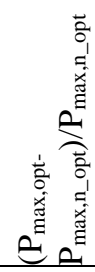 & 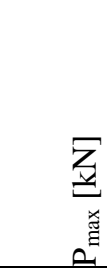 & $\begin{array}{c}r \\
\end{array}$ & 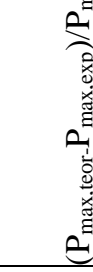 \\
\hline & & & & & & \multicolumn{2}{|c|}{ Teor. } & \multicolumn{2}{|c|}{ Exp. } & & \multicolumn{2}{|c|}{ Teor. } & \multicolumn{2}{|c|}{ Exp. } & \\
\hline 2 & FG & $\mathrm{PW \|}$ & 2 & FG & 10.5 & 1.55 & $10 \%$ & 1.57 & $-6 \%$ & $-1 \%$ & 11.42 & $14 \%$ & 12.49 & $15 \%$ & $-9 \%$ \\
\hline 2 & FG & $\mathrm{PW} \perp$ & 2 & FG & 10.5 & 1.51 & $8 \%$ & 1.68 & $1 \%$ & $-10 \%$ & 11.14 & $17 \%$ & 12.40 & $15 \%$ & $-10 \%$ \\
\hline 2 & FGO & PW & 2 & FGO & 10.5 & 1.39 & & 1.67 & & $-17 \%$ & 13.04 & & 14.33 & & $-9 \%$ \\
\hline 3 & FG & PW\| & 3 & FG & 12.5 & 1.00 & $25 \%$ & 0.98 & $32 \%$ & $2 \%$ & 18.36 & $4 \%$ & 16.12 & $-3 \%$ & $14 \%$ \\
\hline 3 & FG & $\mathrm{PW} \perp$ & 3 & FG & 12.5 & 0.98 & $23 \%$ & 0.93 & $28 \%$ & $5 \%$ & 15.55 & $23 \%$ & 12.96 & $21 \%$ & $20 \%$ \\
\hline 3 & FGO & PW & 3 & FGO & 12.5 & 0.75 & & 0.67 & & $12 \%$ & 19.09 & & 15.64 & & $22 \%$ \\
\hline
\end{tabular}

\section{Conclusions}

The two step optimization method for composite plastic plates is investigated; in first step the fiber directions as well as concentrations in outer layers are optimized. This method provides a possibility to increase plate's stiffness up to $30 \%$

The maximal stress in direction of glass fiber increase for $12 \%$, but the maximal stress in direction of wood fibers decreases for $30 \%$ for the optimized cases.

Experimental investigations approve the optimization method.

In the future there should be created a method that calculates optimal dimensions of discrete domains of the plate.

\section{References}

Akhavan H., Ribeiro P. (2011) Natural modes of vibration of variable stiffness composite laminates with curvilinear fibers. Composite Structures, Vol. 93, No. 11, p. 3040-3047.

Akhavan H., Ribeiro P. (2012) Non-linear vibrations of variable stiffness composite laminated plates. Composite Structures, Vol. 94, No. 8, p. 2424-2432.

Almeida F.S., Awruch A.M. (2009) Design optimization of composite laminated structures using genetic algorithms and finite element analysis. Composite Structures, Vol. 88, No. 3, p. $443-454$.

Asadpoure A., Tootkaboni M., Guest J. K. (2011) Robust topology optimization of structures with uncertainties in stiffness - Application to truss structures. Computers and Structures, Vol. 89, No. 11-12, p. 1131-1141. 
Bank L. C. (2006) Composites for Construction Structural Design with FRP Materials. Jon Wilery \& Sons. 567 p.

Bendsoe M. (1989) Optimal shape design as a material distribution problem. Structural and Multidisciplinary Optimization, Vol. 1, No. 4, p. 193-202.

Clarke J. L. (2005) Structural design of polymer composites. London: E\&FN SPON. 660 p.

Diaz A., Bendsoe M. (1992) Shape optimization of structures for multiple loading conditions using a homogenization method. Structural and Multidisciplinary Optimization, Vol. 4, No. 1, p. 17-22.

Diaz J., Fagiano C., Abdalla M. M., Gurdal Z., Hernandez S. (2012) A study of interlaminar stresses in variable stiffness plates. Composite Structures, Vol. 94, No. 3, p. 1192-1199.

Gurdal Z., Olmedo R. (1993) In-Plane Response of Laminates with Spatially Varying Fiber Orientations: Variable Stiffness Concept. AIAA Journal, Vol. 31, No. 4, p. 751-758.

Hansel W., Treptow A., Becker W., Freisleben B. (2002) A heuristic and a genetic topology optimization algorithm for weight-minimal laminate structures. Composite Structures, Vol. 58, No. 2, p. 287-294.

Hudson C. W., Carruthers J. J., Robinson A. M. (2010) Multiple objective optimization of composite sandwich structures for rail vehicle floor panels. Composite Structures, Vol. 92, No. 9, p. 2077-2082.

Jung H. S., Cho S. (2004) Reliability-based topology optimization of geometrically nonlinear structures with loading and material uncertainties. Finite Element Analysis and Design, Vol. 41, No. 3, p. 311-331.

Kaveh A., Hassani B., Shojaee S., Tavakkoli S. M. (2008) Structural topology optimization using ant colony methodology. Engineering Structures, Vol. 30, No.9, p. 2559-2565.

Keller D. (2010) Optimization of ply angles in laminated composite structures by a hybrid, asynchronous, parallel evolutionary algorithm. Composite Structures, Vol.92, No. 11, p. 2781-2790.

Lund E. (2009) Buckling topology optimization of laminated multi-material composite shell structures, Composite Structures, Vol. 91, No. 2, p. 158-167.
Muc A., Muc-Wierzgon M. (2012) An evolution strategy in structural optimization problems for plates and shells. Composite Structures, Vol. 94, No. 4, p. 1461-1470.

Niu B., Olhoff N., Lund E., Cheng G. (2010) Discrete material optimization of vibrating laminated composite plates for minimum sound radiation. International Journal of Solids and Structures, Vol. 47, No. 16, p. 2097-2114.

Pelletier J. L., Vel S. S. (2006) Multi-objective optimization of fibre reinforced composite laminates for strength, stiffness and minimal mass. Computers and Structures, Vol. 84, No. 29-30, p. 2065-2080.

Sebaey T. A., Lopes C.S., Blanco N., Costa J. (2011) Ant Colony Optimization for dispersed laminated composite panels under biaxial loading. Composite Structures, Vol. 94, No. 1, p. 31-36.

Setoodeh S., Abdalla M. M., IJsselmuiden S. T., Gurdal Z. (2009) Design of variable-stiffness composite panels for maximum buckling load. Composite Structures, Vol. 87, No. 1, p. 109-117.

Sliseris, J.; Rocens, K. 2013. Optimal design of composite plates with discrete variable stiffness, Composite Structures 98 (April): 15-23

Sliseris, J., Rocens K. (2012) Optimization of multispan ribbed plywood plate macro-structure for multiple load cases, Journal of Civil Engineering and Management (accepted to publish).

Sliseris J., Rocens K. (2011) Rational structure of panel with curved plywood ribs. in proceedings of ICBSE 2011: "International Conference on Building Science and Engineering", April, p. 317-323.

Stegmann J., Lund E. (2005) Discrete material optimization of general composite shell structures. International Journal for Numerical Methods in Engineering, Vol. 62, No. 14, p. 2009-2027.

Wang W., Guo S., Chang N., Yang W. (2010) Optimum buckling design of composite stiffened panels using ant colony algorithm. Composite Structures, Vol. 92, No. 3, p. $712-719$. 